\title{
Intersubjetividade e senso comum em Kant 1
}

\author{
Luís F. S. Nascimento \\ Universidade de São Paulo \\ luisfsnascimento@yahoo.com.br
}

resumo Em que sentido pode mos dizer que a noção kantiana de sujeito relacio na-se com uma id é iade intersubjetividade, e em que medida o exame que o filósofo de Königsberg faz da beleza permite entender tal relação? Na tentativa de responder a tal questão (sugerida por comentadores como Géra rd Lebrun e Alexis Philonenko), o presente texto procura entender o vínculo que a Crítica do Juízo estabelece ent re intersubjetivida de e senso comum pela análise dos conceitos kantianos de desinteresse e juízo de gosto.

palavras-chave Kant; Crítica do Juízo; Intersubjetividade; Senso Comum; Beleza; Juízo de Gosto

No segundo parágrafo da Crítica do Juízo, Kant apresenta-nos a seguinte definição de interesse:

"Interesse é denominada a satisfação que vinculamos com a

representação da existência de um objeto” (KANT, 1974, p. 210).

Por esse motivo, diz o filósofo de Königsberg, um juízo que atribui beleza às coisas (um juízo de gosto) terá de ser considerado como desinteressado (uninteressiert), pois embora haja nele representação, nenhum objeto determinado, nenhum conceito, é representado. Estamos, então, diante de um problema, pois como entender a idéia de uma representação que nada rep resenta? É exatamente essa a questão explorada por Gérard Lebrun ao escrever as seguintes linhas sobre o juízo de gosto:

Recebido em 20 de dezembro de 2007. Aceito em 20 de março de 2008.

doispontos, Curitiba, São Carlos, vol. 5, n. 1, p.115-122, abril, 2008 
"Representação de nada, justamente enquanto ela procura se reproduzir. Uma 'blosse Vorstellung' que deixa em mim seu rastro 'enquanto estou consciente dela' - que impõe-se exclusivamente por sua presença e não pelo conteúdo que se anuncia nela... A coisarepresentada sem dúvida suscitou o prazer, mas não é sua representação que o prazer repete (...)" (LEBRUN, 1993, p. 450).

O juízo de gosto é então uma "mera representação" (blosse Vorstellung) na qual a presença da atividade ou capacidade de representar é mais importante do que aquela do objeto que ele julga ou representa. Tentemos aqui entender a questão do gosto em Kant a partir de um exemplo apresentado pelo próprio filósofo de Königsberg no parágrafo 8 da Crítica do Juízo e comentado por Lebrun em Kant e o fim da metafisica, a saber: o juízo "a rosa é bela". O que se diz da rosa quando lhe atribuímos beleza? O predicado belo, diz-nos Kant, não está ligado ao "conceito do objeto, em sua esfera lógica inteira, e, no entanto, ele mesmo se estende sobre a esfera inteira daqueles que julgam" (KANT, op. cit., p.218). A beleza, acrescenta Lebrun, é "um predicado que nenhuma intuição dada preenche" (LEBRUN, 1993, p. 467). Trata-se, assim, de um predicado indeterminado que assinala um uso espontâneo da predicação. Quando digo " a rosa é bela", estou livre para estender o conceito de rosa. A flor que contemplo não é mais única e exclusivamente o órgão reprodutor descrito pelo botânico: ao chamá-la de bela posso agora associá-la aos mais diversos conceitos, tais como o amor, a amizade, a felicidade, a paz etc. Não acrescento qualquer nova informação a respeito dessa flor, nenhum conhecimento é dado quando a vinculo à beleza. Ou seja: a rosa propriamente dita é apenas algo como um suporte a partir do qual desencadeia-se uma predicação livre e indeterminada ou, nas palavras de Kant, desinteressada, isto é: sem me interessar pela representação da existência daquilo sobre o qual julgo, deixo-me envolver pelo simples e mero (bloss) prazer de julgar. Podemos dizer que as obras dos gênios são belas justamente porque suscitam em nós esse mesmo prazer de julgar livremente. De acordo com Kant, a obra de gênio dá muito a pensar (geben zu denken): podemos discutir por horas a fio o sentido de um poema, de um quadro ou de uma música, mas nunca poderemos determiná-los, tal como se fossem o objeto de um juízo de conhecimento. O prazer que experimentamos ao 
contemplar as obras de arte provém de um traço que lhes é peculiar: a capacidade de fazer com que seus admiradores reflitam. Por sua vez refletir, explica Lebrun, "é cessar de conhecer ou de acreditar que se conhece, para entregar-se a uma interp retação espontânea dos conteúdos" (LEBRUN, 1993, p. 458).

Como vimos, uma rosa, um quadro, ou qualquer outro objeto que se julgue belo, são entendidos como uma espécie de pretexto para ativar o uso livre da faculdade de julgar. O objeto mesmo somente suscita essa “interpretação espontânea dos conteúdos”. Ao invés de um objeto determinado, temos aqui um sentimento de prazer que é a manifestação do movimento livre do julgar e, sobretudo, a expressão da consciência que a própria faculdade de julgar tem de sua atividade. Segundo Lebrun, o termo belo designa essa "consciência não-cognoscente e como que fascinada por si mesma” (ib., p. 449). Daí o caráter eminentemente reflexionante de um juízo de gosto. Nele, a faculdade de julgar julga a si mesma e fascina-se com o seu próprio poder. Do ponto de vista da lógica, diznos Lebrun, um tal juízo permanecerá sempre uma contradição. Ao fazer de si mesma o seu objeto, a faculdade de julgar instaura um paradoxo não se pode determinar o objeto, pois ele é ao mesmo tempo aquele que julga. No lugar que normalmente é reservado à passividade de um objeto que se deixa determinar, encontramos agora uma faculdade que não pára de atuar (spielen). Por essa razão, o juízo de gosto terá de ser entendido como subjetivo: um jogo (Spiel) do sujeito consigo mesmo, mas que, justamente por ser subjetivo, torna-se de extrema importância para toda a objetividade possível:

"Os poderes-de-conhecimento [a imaginação e o entendimento] que são postos em jogo por essa representação [aquela do gosto] estão nesse caso em um livre jogo, pois nenhum conceito determinado os restringe a uma regra particular de conhecimento. Portanto, o estado-da-mente nessa representação tem de ser o de um sentimento do livre jogo dos poderes-de-representação em uma dada representação, para um conhecimento em geral (Erkenntnisse überhaupt). Ora, pertence a uma representação, pela qual um objeto é dado, para que em geral haja a partir disso conhecimento, imaginação para a composição do diverso da intuição e entendimento para a unidade do conceito que unifica as representações" (KANT, 1974, p. 220, grifo nosso). 


\section{8}

No juízo de gosto, as faculdades que trabalham para a constituição do conhecimento em geral (imaginação e entendimento) atuam liv remente, isto é: sem a restrição de nenhuma regra particular do conhecimento, como nos mostrou o trecho acima citado. Para Kant, dizer que existe um estado no qual imaginação e entendimento estão em um livre jogo, é reconhecer que há entre eles um acordo ou "concordância mútua" (wechselseitige Zusammenstimmung) que antecede e possibilita qualquer conhecimento que juntos eles poderão produzir. No limite, a livre produção de conteúdos e predicados que permite um juízo de gosto (tal como vimos a partir do exemplo da rosa) é tão-somente a expressão ou manifestação desse acordo originário entre as faculdades de conhecimento. O gosto não é apenas a constatação de que há um livre jogo entre imaginação e entendimento (e que, portanto, existe um vínculo originário entre tais faculdades), ele também pode ser compreendido como a manutenção desse jogo. Como diz o autor da Crítica do Juízo, o acordo das faculdades é algo ativo, p recisa ser "repetido" ou "recolocado" para ser mantido. É revivendo esse acordo que o espírito é vivificado (belebt, é o termo utilizado por Kant), é assim que ele (o espírito) torna-se consciente de sua própria capacidade cognoscente: um momento em que o sujeito contempla e, de certa maneira, compreende sua força ou os seus podere s. O gosto é então uma "auto-fruição" do sujeito, que se contenta ao observar as faculdades de conhecimento em um instante em que elas nada conhecem: um "prazer de reflexão", na expressão de Kant. Não é por acaso que Lebrun diz que o juízo de gosto pode ser considerado como um Vorurteil (um "préjuízo") ou um Urbild (um protótipo) para todo e qualquer juízo de conhecimento, uma vez que nele a própria forma do julgar é evidenciada. "A 'Form”, diz-nos Lebrun, “é aquilo que já se anuncia a um sujeito apenas consciente, e que lhe permite orientar-se na desordem da présubjetividade" (LEBRUN, 1993, p. 461). Ainda não existe no nível da pré-objetividade nenhuma regra precisa ou fixa que determine a atuação das faculdades de conhecimento, mas isso não quer dizer que se trata de uma completa desordem - já há ali (como afirma Lebrun) uma forma: umaconsciência de que as faculdades tendem a trabalhar em conjunto, de que existe um acordo entre elas. Nesse sentido, o liv re jogo não é assim tão desregrado quanto pode parecer em primeiro momento. Por certo, 
ele não se submete a nenhuma lei que determine com precisão o modo como atua. No entanto, há nele algo como uma "regra liv re e indeterminada" ou (nas palavras de Lebrun) uma Grundmass (uma "medida fundamental"), uma fo rma do julgar que tende a se perpetuar e a se repetir. Trata-se, portanto, de uma auto-regulamentação espontânea da faculdade de julgar, que se ajusta ou se reajusta a cada instante de sua atuação: um movimento livre do qual o juízo de gosto é o melhor paradigma, de acordo com o autor de Kant e o fim da metafísica. Ainda com Lebrun, podemos dizer que existe em nossa faculdade de julgar uma Naturabsicht: uma "intenção natural", entendendo aqui o termo "intenção" como sinônimo de "tendência" ou "disposição". Ou seja: por natureza, nossa faculdade de julgar tende a julgar ou a continuar a julgar. Mesmo quando nossos juízos não se orientam por nenhuma regra determinada, quando emitimos um juízo de gosto e, por exemplo, associamos liv remente conceitos tão distintos quanto o de rosa e o de amor, ainda assim a disposição ou a tendência a julgar permanece como um fio condutor ou uma "medida fundamental" (Grundmass) de todo juízo.

O livre jogo ou "concordância recíproca" (KANT, 1974, p. 221) entre imaginação e entendimento é a expressão mais original dessa tendência natural do sujeito: ainda que desinteressadamente, as faculdades de conhecimento atuam e o sujeito julga. Antes mesmo de determinar um objeto, entendimento e imaginação já se mostram dispostos a atuar juntos. A efetivação de um juízo objetivo apenas atesta a presença do liv re jogo que permanece sendo o princípio subjetivo de toda objetividade ou, nas palavras de Kant, "esta proporção subjetiva apropriada para o conhecimento em geral” (ib., p. 220). Essa “proporção”, acrescenta o parágrafo 9 da Crítica do juízo, "tem de valer igualmente para todos e, conseqüentemente, ser universalmente comunicável, tanto quanto o é cada conhecimento determinado, que sempre repousa sobre essa proporção como condição subjetiva" (id., ibid.). E é assim que o gosto (como manifestação da consciência subjetiva da proporção entre imaginação e entendimento) chega à idéia de um senso comum (Gemeinsinn). De acordo com Kant, não há como chegar à consciência de um acordo entre imaginação e entendimento e vivenciar (beleben) o prazer que uma tal constatação desperta, sem pressupor que se trata de algo que deve ser compartilhado ou comunicado (mitteilen) com os outros homens. Como 
afirma o filósofo de Königsberg, a pressuposição da idéia de uma comunidade não é externa ou alheia ao gosto - ela nasce nele e com ele:

"Portanto, somente sob a pressuposição de que haja um senso-comum (pelo que, porém, não entendemos nenhum sentido externo, mas o efeito do livre jogo de nossos poderes-de-conhecimento), somente sob a pressuposição, digo eu, de um tal senso-comum pode o juízo-degosto ser emitido" (KANT, 1974, p. 236).

Sem a pressuposição de uma comunicabilidade ou senso comum, não existe gosto, não há consciência do acordo entre imaginação e entendimento e, no limite, toda a universalidade a qual o conhecimento objetivo pretende também estará fadada ao fracasso. Portanto, para que um juízo de conhecimento seja universalmente válido, é necessário que as condições subjetivas que o fundamentam também o sejam. Isto é: é preciso postular um senso comum como uma validade pré-objetiva, como uma universalidade subjetiva:

"Podemos com razão admitir um senso-comum (Gemeinsinn), mesmo sem nos fundarmos em observações psicológicas, mas enquanto a condição necessária da comunicabilidade universal de nosso conhecimento, que deve ser pressuposta em toda lógica e para todo princípio dos conhecimentos que não seja cético" (KANT, K.U., \ 21. V, 239 apud LEBRUN, 1993, p. 496).

O senso comum pressuposto pelo gosto não é a sociedade real, o local onde vivemos: ele é uma idéia. O gosto não se dirige ao reino das opiniões (sempre discordantes) dos homens, mas à humanidade em geral. Ao emitir o seu juízo de gosto, um homem pode estar totalmente contra a opinião reinante em sua época e, no entanto, d eve estar convicto de que fala em nome de algo maior - o gênero humano. Lebrun destaca os exemplos de Rousseau (que contra cada um dos homens em particular, es c revia para todos em geral) e o de Stendhal (que dizia que apenas seria compreendido anos depois de sua morte e que escrevia para um leitor futuro e ideal). No momento em que profiro o meu juízo de gosto, p ressuponho que toda uma comunidade irá confirmar o meu veredicto. Para dizer que uma rosa é bela, eu preciso pressupor que todos os seres capazes de julgar chegariam à mesma conclusão caso a contem- 
plassem. Meu juízo de gosto sequer existiria se eu não pudesse partir da idéia de que falo por toda a humanidade - eis aí a validade do meu juízo: uma validade subjetiva, mas que não deixa de ser universal na medida em que tem de ser compreendida como um atributo de todos. Em princípio, todos os sujeitos são capazes de julgar ou tendem a julgar, todos têm imaginação e entendimento e em todos eles essas faculdades possuem um acordo espontâneo e original, a partir do qual podem atuar juntas e produzir conhecimento. O juízo de gosto exige essa idéia de comunidade e comunicabilidade entre os homens. Há sempre a pressuposição de um senso comum, definido da seguinte maneira pelo parágrafo 40 da Crítica do Juízo:

“(...) faculdade de julgar que, na reflexão, leva em consideração em seus pensamentos, a priori, o modo de representação de todos os outros para apoiar seu juízo na razão humana coletiva” (KANT, K.U., $\mathbb{S} 40$ apud LEBRUN, 1993, p. 500).

O senso comum é então a própria faculdade de julgar que, em um mov imento espontâneo e liv re, contempla-se e reconhece nessa ação aquilo que a torna universal: o seu pertencimento a uma comunidade, à humanidade. O próprio desdobramento da faculdade (esse "voltar-se para si", "contemplar-se") permite que se chegue à idéia de um outro com quem o sujeito estabelece um vínculo ou comunicação. Como diz Lebrun: “(...) a consciência universal vê-se a si mesma neste outro, cuja singularidade já está suprimida pelo fato de ser confessada; a humanidade do outro é a realização daquilo que, nela, não era senão vã pretensão" (LEBRUN, 1993, p. 502).

A consciência daquilo que me torna sujeito (minha capacidade de julgar) depende da idéia de um "outro": uma comunidade a qual pertenço ou, antes, pressuponho pertencer. "Logo", a c rescenta Lebrun, "no momento em que mais pareço curvar-me sobre minha singularidade, eu me sinto universal" (id., p. 489).

Para que o sujeito possa entender e realizar aquilo que o faz ser um sujeito, ele precisa olhar para si mesmo: contemplar-se, fazer de si mesmo um outro. $\mathrm{O}$ movimento da reflexão exige uma distância (o sujeito afasta-se de si para se ver), mas, ao mesmo tempo, requer uma aproximação é com esse estranho que o sujeito comunica-se: esse outro, que surge em 
seu próprio interior, é o seu interlocutor. Desse ponto de vista, para que possa estar consciente de sua subjetividade, o sujeito kantiano tem de ser vários: ser "plural" 2 . Ou antes: estar em meio a vários, comunicar-se, falar por um universo. Eis aí o sentido dessa universalidade que se manifesta todas as vezes que julgamos algo belo.

${ }^{1}$ Esse texto foi apresentado no Colóquio Structure, système, subjectivité, realizado na Universidade Blaise Pascal, Clermont-Ferrand, 2006.

2 É o que afirma Alexis Philonenko ao comentar a "problemática da intersubjetividade" (la problématique de l'intersubjectivité) em Kant: "De todos os pós-kantianos, Fichte será talvez aquele que perceberá mais claramente esse princípio de unidade do criticismo, que se poderia exprimir ao dizer que o cogito kantiano é um cogito plural” (PHILONENKO, 2000, p.20).

\section{Referências bibliográficas}

LEBRUN, G. 1993. Kant e o fim da metafísica. Tradução de Carlos Alberto Ribeiro de Moura. São Paulo: Martins Fontes.

KANT, I. 1974. Analítica do belo. Tradução de Rubens Rodrigues Torres Filho. São Paulo: Editora Abril.

KANT, I. 1990. Kritik der Urteilskraft. Hamburgo: Felix Meiner Verlag. PHILONENKO, A. 2000. “Introduction”. In: KANT, I. Critique de la faculté de juger. Tradução de Alexis Philonenko. Paris: J.Vrin. 